\title{
Effects of Different Cultural Backgrounds and Co-ethnicity on Interpersonal Interactions among Students from Different Cultures and Nationalities at a Malaysian Public University
}

\author{
Abdul Qahar Sarwari ${ }^{\mathrm{a} *}$, Ainol Haryati Bt Ibrahim ${ }^{\mathrm{a}}$, Nor Ashikin Abdul Aziz ${ }^{\mathrm{a}}$ \\ ${ }^{a}$ Center for Modern Languages and Human Sciences (CMLHS), University Malaysia Pahang (UMP), \\ Lebuhraya Tun Razak, 26300 Gambang, Kuantan, Pahang, Malaysia.
}

\begin{abstract}
This study was conducted to evaluate the effects of different cultural backgrounds and co-ethnicity on the process of interpersonal communication (IPC) among local and international students of University Malaysia Pahang (UMP). An embedded design of mixed methods was applied to conduct this study. The quantitative survey was conducted as the main method of this study and the qualitative interviews were done to enrich the data. The quantitative survey had 220 participants from both Malaysian and international students of $U M P$, and 12 of them were interviewed for the qualitative data as well. According to the results, the vast majority of participants reported that their different cultural backgrounds had positive effects on their interactions with students from different nationalities and their interactions with different people enabled them to gain some new cultural information. Findings of this study also confirmed the helpful influence of coethnicity on interactions among students who had students from their own ethnicities and tribes among local or foreign students of UMP. The results are supportive of the positive effects of cultural and tribal diversities of both local and international students of UMP on their daily interactions. Findings of this study may encourage university students to be involved in interactions with students from different cultures and ethnicities to experience the new multicultural environments and improve their social skills through their interactions with people from different societies.
\end{abstract}

Keywords: Different cultural backgrounds; co-ethnicity; Interpersonal communication; interactions

\section{Introduction}

According to Marr (2009), interpersonal communication (IPC) is a verbal and nonverbal exchange that takes place between/among two or more people in a face-to-face encounter. Interpersonal Interactions among students from different cultures, nationalities and ethnicities help them to learn some new cultural information and improve their communication skills. As argued by Izumi (2010), understanding of the sense of other people's life is one of the main aims to go and study in another country. Interactions among students from different ethnicities and cultures at the collegiate environments also may pave the ways for them to have more academic achievements, and experience connections with the multicultural networks of students in their life. As argued by Lusting \& Koester (2006, as cited in Gao, 2011), the ability of interacting with people from different cultural backgrounds is an important skill of both public and private lives. And according to Chickering\&Reisser (1993, as cited in Aidoo, 2012), to increase the fruitful relations with people from different backgrounds, students might be needy of several manners and skills, like tolerance and communication competence.

The above mentioned statements of some previous researchers illustrate the importance of daily interactions among students from different cultures and nationalities, and ask them to seize all opportunities to improve their personal and academic lives. Although, some previous researchers (e.g. Aidoo, 2012; Izumi, 2010; Huang, 2010; Abdullah, 2008) conducted studies on the related issues, but their findings belonged to the countries which have fundamental differences from Malaysia and some other Asian countries and do not answer the questions on the process of daily interactions among local and international students of Malaysian universities; therefore, this study was conducted to evaluate interactions among local and international students of a Malaysian public university, UMP. Findings of this study may help university students to know the main factors which affect the process of their interactions, and may help the future researchers to have more focus on their studies in the related issues.

\subsection{Aim of Study}

Aim of this study was to evaluate the effects of different cultural backgrounds and co-ethnicity on the process of interpersonal interactions among local and international students of University Malaysia Pahang (UMP). 


\subsection{Significance Of Study}

Findings of this study may answer some questions on interactions among local and international students of Malaysian universities and effects of different cultural and tribal backgrounds on this process. Findings of this study also may encourage university students to be involved in interactions with students from different cultures and nationalities, and help the future researchers to further the information.

\section{Literature Review}

IPC is among essential aspects of modern life for all human beings, especially university students. According to Marr (2009), in spite of progress in opportunities of interactions, IPC kept constant of its usage and practice. The ability to have good interactions at the university environment also may help students to be happier and learn more. IPC may assist students to expand their skills in communication and community building and its impact is much more important than mass communication (Gao, 2011; Aidoo, 2012; Dixon, 2001 cited in Aidoo, 2012; Lusting \& Koester, 2006 cited in Gao, 2011; Gudykunst\& Kim, 2003 cited in Gao, 2011). IPC among students from different countries and different cultures may pave the ways for them to share their knowledge, information, experiences, and also participation of university students in IPC may improve their private and professional lives. As asserted by Aidoo (2012), interpersonal relations or understanding at university may improve individual and professional lives of students. Nowadays, enough skills of IPC are required for all educated people to find their demanded jobs and be successful in their occupations. In the 21 st century all educational and business-related works are paying high value on the employees and educated people who have enough skills on IPC; therefore, communications and gatherings of students at the university may bring the required skills, when students cooperating with people of several societies (House, 2004 cited in Aidoo, 2012; Crowell, 2011; Aidoo, 2012).

Modern educational norms may have effects on improvement of the abilities of students. As argued, a liberal style of education may promote self-awareness, and increase individual, cultural, intellectual, and public interests, and challenging belief and prejudgment; and also emerging personal, ethical and moral norms while making students to participate in an open society (Pascarella\&Terenzini, 2005 as cited in Aidoo, 2012). Based on the assumptions of communicators and communicative environments, daily interactions with different people may have different results. As asserted by Abdullah (2008), different cultural backgrounds were known as restrictive toward increase of friendships among different cultures, as feelings of how to spend free times, life priorities, or even general themes of interests were different from Americans to Arabs. In a survey of intercultural communication competence of Chinese students in some higher education institutions of the United States, GAO (2011) found that, the high level of direct IPC with the host people had negative effects on the level of face-to-face interactions with their co-ethnic people. Based on the findings of a qualitative study of daily interactions between Japanese and American students in the American higher education institutions, Izumi (2010) stated as, it became clear that Japanese students in the U.S. instead of coping with different cultures in the multi-cultural environment of the United States and increasing of their intercultural communication competence, struggle to keep their own cultural and communicative norms. According to the literature, daily IPC at the collegiate environments with different people is among important education related issues and worthy to be evaluated.

\section{Method}

An embedded design of mixed methods was applied, and the main method for this study was quantitative survey and qualitative interviews were done to enrich data. The embedded design was achieved through conducting of the quantitative survey and embedding of qualitative interviews into it, also the quantitative data was collected directly and through random data collection process in a time period of 5 weeks. According to Creswell \& Plano Clark (2007), the researchers use embedded design when they need to encompass the findings of survey or interviews to answer a question in the quantitative or the qualitative method in a large scale.

\subsection{Instruments}

The quantitative questionnaires, demographic information, and a package of unstructured interview questions were the main instruments for this study. The quantitative questionnaires were designed based on the Likert's scale with 4 options per each item, and 12 open ended questions were prepared to conduct the interviews. All instruments were prepared by the researcher with the reference to instruments of some previous works, as (Aidoo, 2012; Gao, 2011; Huang, 2010).

\subsection{Data Collection Procedure}

The quantitative data were collected through direct and random distribution of survey questionnaires to the participants. The qualitative interviews were done directly and individually and all interviews were recorded. 
The main locations for the data collection procedure of this study were library, hostel and cafeteria of UMP's Gambang campus. UMP is a public engineering-dominated Malaysian university and has two campuses which located in Gambang and Pekan areas of Pahang state of Malaysia. This study was applied at the Gambang campus of UMP, because almost all international students of UMP were settled at this campus.

\subsection{Participants}

The quantitative survey had 220 participants from both local and international students of UMP as 110 Malaysians and 110 foreign students. Malaysian participants of this study belonged to almost all parts of the country with their different ethnicity and social backgrounds. International participants of this study belonged to 16 different countries also with their different religious, cultural and ethnicity backgrounds. According to Wiersma\&Jurs (2005), sampling of participants helps the researchers to choose a particular number of participants which can represent all estimated population and their answers can be generalized to all population.

\section{Findings}

The quantitative data were examined through the essential options of SPSS. The qualitative interviews were analyzed separately and the findings were categorized into categories and sub-categories based on the research-, and interview-questions and themes which found from the answers of interviewees.

\subsection{Quantitative Findings}

The reliability test of SPSS applied to check reliability of the instruments and Cronbach's alpha rating for all items together was .707. A descriptive test was conducted to find out the demographic information and Table 1 bellow illustrates the demographic information of both Malaysian and international participants of this study.

Table 1: Demographic information of participants

\begin{tabular}{|c|c|c|c|c|}
\hline Variable & Malaysian & International & Total & $\begin{array}{l}\text { Percent } \\
\%\end{array}$ \\
\hline \multicolumn{5}{|l|}{ Classification } \\
\hline Malaysian & & & 110 & 50 \\
\hline International & & & 110 & 50 \\
\hline \multicolumn{5}{|l|}{ Gender } \\
\hline Male & 50 & 97 & 147 & 66.8 \\
\hline \multicolumn{5}{|l|}{ Age Category } \\
\hline $18-22$ & 76 & 19 & 95 & 43.2 \\
\hline $23-29$ & 34 & 53 & 87 & 39.5 \\
\hline $30-37$ & . & 24 & 24 & 10.9 \\
\hline $37+$ & . & 14 & 14 & 6.4 \\
\hline \multicolumn{5}{|l|}{ Education Level } \\
\hline Degree $1^{\text {st }}$ year & 38 & 18 & 56 & 25.5 \\
\hline Degree $2^{\text {nd }}$ year & 20 & 2 & 22 & 10 \\
\hline Degree $3^{\text {rd }}$ year & 34 & 5 & 39 & 17.7 \\
\hline Degree $4^{\text {th }}$ year & 15 & 9 & 24 & 10.9 \\
\hline Master's & 3 & 31 & 34 & 15.5 \\
\hline $\mathrm{PhD}$ & . & 45 & 45 & 20.5 \\
\hline \multicolumn{5}{|l|}{ ELP } \\
\hline Poor (4.0 or less) & 16 & 3 & 19 & 8.6 \\
\hline Good (4.5-5.0) & 85 & 60 & 145 & 65.9 \\
\hline V. $\operatorname{good}(5.0-6.0)$ & 7 & 41 & 48 & 21.8 \\
\hline Excellent $(6.0+)$ & 2 & 6 & 8 & 3.6 \\
\hline
\end{tabular}

Based on the results of the descriptive test for the demographic information, this study had 220 participants from both local and international students of UMP, as 110 local and 110 international. From 220 participants, 147 of them were male and 73 others were female. From male participants, 97 of them were international and 50 other Malaysian, also from female participants, 60 of them were local and 13 from international students of UMP. From 110 Malaysian participants of the quantitative survey, 82 of them were Malay-Malaysians, 18 Chinese-Malaysians, and 8 of them were Indian-Malaysians. And 110 international participants also belonged to 16 different countries, and table 2 illustrates frequencies based on their countries. 
Effects of different cultural backgrounds and co-ethnicity on Interpersonal Interactions among

Tab.2. frequencies of international participants based on their countries

\begin{tabular}{lclc}
\hline Country & Frequency & Country & Frequency \\
\hline China & 18 & Libya & 6 \\
Indonesia & 13 & Nigeria & 5 \\
Iraq & 13 & Sudan & 4 \\
Yemen & 13 & Algeria & 1 \\
Afghanistan & 10 & Canada & 1 \\
Pakistan & 9 & Egypt & 1 \\
India & 8 & Iran & 1 \\
\hline
\end{tabular}

From all 14 items of the quantitative section of interpersonal communication competence (IPCC) items, 5 items covered the quantitative results for the purpose of this paper. Frequencies of answers of the participants for these items were examined through descriptive test, and based on that as the positive factors on the process of IPC among students of different countries and ethnicities at UMP, $80.4 \%$ of participants already experienced some interactions with people of different culture and nationalities, and from 220 participants, 188 of them agreed that their interactions with students of different nationalities helped them to have some collaborative learning and activities at the university campus. From 220 participants, 207 of them were happy when interacted with different people, and the vast majority of participants $(78.2 \%)$ accepted that they interact with their classmates regardless of their countries and ethnicities. From 220 participants, 197 of them accepted that their daily IPCs were very useful for their private and public lives, and $83.1 \%$ of them agreed that they learned some essential communication skills from their IPCs with local/international students during their stay and study at UMP. About $90 \%$ of participants also accepted that they feel comfortable during their IPCs with people of different countries and ethnicities.

The items that covered the quantitative section of this paper were grouped through the transform option of SPSS to find-out their statistical mean score and conduct t-tests for the classification (Malaysian and international) and gender (male and female) variables to compare the mean scores of their indicators. The independent-samples t-test was applied to compare the mean scores of Malaysians to international participants of this study and no significant difference found as $\mathrm{t}(218)=1.563, \mathrm{p}>.05$, also mean/standard deviation score for Malaysians was $1.97 / .42$ and for international participant was $1.88 / .43$. The same test was conducted to compare mean scores of male to female participants and no significant difference found as well, as t (218) = $.080, \mathrm{p}>.05$, and mean scores for male and female participants were 1.92/.44, and 1.93/.41 respectively.

\subsection{Qualitative Findings}

From participants of the quantitative survey, based on their personal agreements, 12 of them were interviewed for the qualitative section of this study. From 12 interviewees, 6 of them were from Malaysian and 6 others from international participants. From 6 Malaysian participants, 3 of them were Malay-Malaysian, 2 Indian-Malaysian and 1 Chinese-Malaysian. International interviewees were from 6 different countries, one participant per each country and from different parts of the world. The countries of international participants were: Afghanistan, India, Algeria, China, Yemen, and Nigeria, and all of them were male students.

In the results of qualitative data, the participants will be mentioned as MSX(X for number of the student) for Malaysian participants and ISX for international students. Both local and international participants of this study been coded as 1) MS1, a Master's Malay-Malaysian student, 2) MS2, a degree Malay-Malaysian student, 3) MS3, a degree Indian -Malaysian student, 4) MS4, a degree Indian-Malaysian student, 5) MS5, a degree Malay-Malaysian student, and 6) MS6, a senior degree Chinese-Malaysian student. International interviewees as 1) IS1, a master's student from Afghanistan, 2) IS2, a PhD student from India, 3) IS3, a PhD student from Algeria, 4) IS4, a senior degree student from China, 5) IS5, a degree student from Yemen, and 6) IS6, a master's students from Nigeria. The coding system for this section was adapted from AinolHaryati Bt. Ibrahim (2011). From the main themes and sub-categories which found from the results of the qualitative data 2 of them were related to topic of this paper and included in the qualitative results which are: 1) Co-ethnicity and 2) Different Cultural and Religious Backgrounds.

\subsubsection{Co-ethnicity}

Almost all of those Malaysian and international participants, who had students of their own coethnicities at the UMP campus told that presence of their co-ethnic people among Malaysian/international students helped them to have more interactions with students of other ethnicities, and find the chances to have, increase, and continue their interactions as well. For example, participant IS2 told that "My ethnicity and race relation with my co-ethnic Malaysian students have positive effects on my communication with Malaysian students and it attracts me to have more interactions with other Malaysian students, rather than my co-ethnic people." The more I interact with [my] co-ethnic group, the more I interact with other groups as well" IS2. 
About effects of his co-ethnic people at the UMP campus, participant MS3 said that "I have my Indian co-ethnic people among international students but it effects my communication positively and helps me to have more communication with other international students." Moreover, participant IS4 told that "Local ChineseMalaysians help me to understand the messages, language and have more communication with other Malaysian students of UMP." MS6 also asserted that "My co-ethnic Chinese help me to have communication with all international students." But, MS4 had the statement as "I don't care of my co-ethnic people or other nations and ethnicities when I want to interact." According this statement, some students do not care of their tribal relations.

\subsubsection{Different Cultural and Religious Backgrounds}

Statements of almost all participants of qualitative interviews illustrated that their different cultural and religious backgrounds had positive effects on the process of their daily interactions with different people at the University environment. According to the answers of interviewees, their interactions helped them to learn some new things and improve the quality of their academic life. For example, as participant MS4 said "interactions with them [international students] help me to learn about their cultures." Participant MS5 pointed out that "As we have different ideas and cultures, therefore, my communication with international students helps me to learn more things and also [to] improve my English [language] by talking with them." And these statements were supported by views of MS4 as said "interacts with international students help me to learn some new things." These statements are also supportive the quantitative data.

Furthermore, according to some Muslim participants, their religion had positive effects on their daily interactions with people of different countries, and almost all of the participants accepted that cultural and traditional norms had no any negative effects on the process of their daily IPCs. As MS1 asserted "My religion helps me to have a good interpersonal communication with international students." IS2 believed that "Religion and other factors do not affect the communication process negatively." His statement supported by assertion of IS4 as said "Different cultures are not a problem to have communications, but we have to know the limitations, as I am a non-Muslim, have to know about Muslims." According to assertions of the interviewees, their cultural and religious norms had positive effect on their daily interactions and mostly the qualitative findings of this study were supportive of the quantitative data.

\section{Discussion and Recommendations}

This research project examined the effects of different cultural backgrounds and co-ethnicity on the process of interpersonal communication (IPC) among local and international students of a Malaysian public higher education institution, University Malaysia Pahang (UMP). According to the results of this study, coethnicity, and different cultural norms had positive effects on the process of IPC among local and international students of UMP, and these factors helped them to increase the level and quality of their daily interactions with students from different ethnicities and countries. Based on the quantitative findings, the vast majority of participants accepted that they already experienced some interactions with students from different cultures and countries, and were happy from their interactions at the university campus. Almost all participants of this study accepted that they learned some essential social skills through their interactions with different people, and their IPC had positive effects on their personal and academic lives as well. About $90 \%$ participants of the quantitative survey also reported that they felt comfortable during their interactions with people from different cultures and nationalities. All of the above mentioned results clearly confirm that the different cultural and social backgrounds of students had helpful impacts on their interactions. The results also confirm that their different cultural, tribal and religious backgrounds and norms helped both local and international students of UMP to gain some new skills and experience the real aspects of a multicultural environment. The above mentioned results are all supportive of the positive effects of interactions among local and international students of UMP on their university related life.

According to the assertions of qualitative interviewees, presence of their co-ethnic people (for both Malaysian and foreign Chinese and Indians) among Malaysian/international students of UMP, and their religion (for Muslim participants) helped them to have more interactions with people from different ethnicities and cultures. In other words, according to answers of both local and foreign students who had their co-ethnic people among UMP students, presence of their co-ethnic people at the university campus paved the ways for them to have more interactions with different people. For example, as asserted by some of the qualitative interviewees, their co-ethnic people among local students of UMP helped international students to interact with other Malaysian students as well, and vice versa. To compare findings of study with the results of some previous studies on the related issues in other countries like the United States, for example in a qualitative study of cultural experiences of Arab and American students of American colleges from different cultures, Abdullah (2008) found that, different cultural backgrounds issue was known as a restrictive to closeness of friendships among people from different cultures, as feelings of how to spend free times, life priorities, or even general themes of interests were different from Americans to Arabs. This argument was not supported by the findings 
of this study, as the results of this study confirmed that the different cultural, religious and tribal backgrounds had positive effect on the process of interactions among local and international students of UMP.

In a survey of intercultural communication competence of Chinese students in some higher education institutions of the United States, Gao (2011) also found that, the high level of direct interactions with the host people had negative effects on the level of face-to-face interactions with co-ethnic people, or in other words, communicators with more interactions with host communicators will have less contacts with their co-ethnic people. But, findings of this study regarding the co-ethnicity issue are completely opposite from assertion of Gao (2011), as almost all interviewees of this study reported that, presence of their co-ethnic people among Malaysian/international students for both local and international students at UMP campus had no any negative effect on their daily interactions, and even it helped them to be involved in more interactions and increase the level of their IPC with other people by the help of students of their own co-ethnicities and languages. According to findings of a qualitative study of the situation of intercultural communication of Japanese students with their American counterparts in the United States, Izumi (2010) argued that, it became clear that the Japanese students at the U.S. universities instead of coping with different cultures in the multi-cultural environment of the United States and increase of their intercultural communication competence, they struggle to keep their own cultural and communicative norms. While, this study found that almost all participants of both quantitative and qualitative sections had willingness to have enough interactions with people of different cultures and countries to gain some new cultural information about other people and learn the essential skills in communication as well. In the other words, gaining of awareness and information from different cultures and learning of new skills in communication from different people were among the main causes that encouraged both local and international participants of this study to have and continue their interactions with students from other cultures and nationalities at the university campus.

The mentioned researchers pointed out the negative results of the different cultures and co-ethnicities on interactions among students from different cultures and nationalities in the host countries. But, Findings of this study supportive of the positive effects of different cultural and religious norms, and presence of co-ethnic people of both local and foreign students at the UMP, as for international students, presence of their co-ethnic people among Malaysians, had positive effects on the process of their daily interactions. For this purpose, the researcher acknowledges that as the above mentioned studies were conducted at the American universities and the fundamental differences of social and cultural norms between the United States and Malaysia caused the differences on the results. As American students are more open-minded and familiar with multicultural environment of the United States, whereas their foreign counterparts from Japan, China and Middle-east are more conservative and brought-up with their traditional backgrounds. While, almost all international participants of this study were from some Asian countries which have many social, religious and cultural similarities with Malaysian people. However, most of the above mentioned findings of this study are new and may be helpful for university students, officials of higher education institutions, and the future researchers.

\subsection{Recommendations}

Interactions among students from different cultures and nationalities at the Malaysian universities and factors that affect this process are always interesting; therefore, more studies on related issues can be done in the future. As this study was conducted at a Malaysian university which almost all of its international students were from Asian countries, hence the same study at the Malaysian universities with more international students from different parts of the world may bring different results and may be useful to be conducted. Effects of interactions among students from different nationalities on establishment of intercultural relations among different nations also would be an interesting issue for the future researchers to be evaluated.

\section{Conclusion}

This study was evaluated the effects of different cultural and tribal backgrounds on interpersonal communication (IPC) among local and international students of University Malaysia Pahang (UMP). According to the results, different cultural backgrounds and co-ethnicity of UMP students had positive effects on their interactions at the university campus. The results also confirmed that, both local and international students of UMP already experienced some interactions with students from different cultures and nationalities at the university campus, and wanted to continue it. Based on the findings, presence of their co-ethnic people at the university environment, and their different social and cultural norms helped both local and international students of UMP to be involved in more interactions with students from other nationalities and gain some essential social and cultural information as well. Participation of 220 students from different cultures, nationalities, and social norms enabled this study to bring views of different people on a manuscript and illustrate the common values and points of views among them. Findings of this study may be helpful for university students, university policymakers and researchers in the future, but still many questions on the related issues are open to be answered. 


\section{Acknowledgements}

This research project was sponsored by SHEP project of Higher Education Ministry of Afghanistan in collaboration with University Malaysia Pahang (UMP).

\section{References}

[1] Abdulla, E. A. (2008). Transcending Ethnocentrism: A phenomenological study of Arab and American college students who experienced the other culture (Doctoral dissertation).Available from ProQuest Dissertations \& Theses database. (UMI No. 3337350)

[2] Aidoo, B. (2012). An examination of mature interpersonal relationships among international and American college students ( Doctoral dissertation). Available from ProQuest Dissertations \& Theses database. (UMI No.3534803)

[3] AinolHaryatiBt Ibrahim. (2011). Podcasting as a tool in the development of public speaking skills.Unpublished doctoral dissertation, International Islamic University Malaysia.

[4] Chickering, A. W., \&Reisser, L. (1993).Education and identity (2nd ed.) San Francisco,CA: Jossey- Bass.

[5] Creswell, J. W. \& Plano Clark, V. L. (2007). Designing and conducting mixedmethodsresearch.Thousand Oaks, CA: Sage.

[6] Crowell, D. M. (2011).Bridging the gap between interpersonal communication skill differences in employees: An interpersonal communication training curriculum (MA dissertation). Available from ProQuest Dissertations \& Theses database. (UMI No. 1503888)

[7] Dixon, B. (2001). Student affairs in an increasingly multicultural world.In R. B. Winston, Jr., D. G. Creamer, T. K. Miller, \& Associates (Eds.), The student affairs administrator: Educator, leader, \& manager (pp. 65-80). Lillington, NC: Taylor \& Francis.

[8] Gao, C. (2011). The role of face-to-face interpersonal communication with different social networks in the development of intercultural communication competence (MA dissertation). Available from ProQuest dissertations \& Theses database. (UMI No. 1494564)

[9] Gudykunst, W. B., \& Kim, Y. Y. (2003).Communicating with strangers: An approach to intercultural communication (4th. ed.). NY: McGraw-Hill.

[10] House, R. J. (2004). Illustrative examples of GLOBE findings. In R. J. House et al. (Eds.),Culture, leadership and organizations: The GLOBE study of 62 societies (pp. 3-8). Thousand Oaks, CA: Sage Publications, Inc.

[11] Huang, Y. ( 2010 ). Acculturation and academic performance: the role of media use and interpersonal communication among international students (Doctoral dissertation ). Available from ProQuest Dissertations \& These database.( UMI No. 3407905)

[12] Izumi,S.(2010). Intercultural communication of identity: a study of Japanese international students in the United Sates (Doctoral dissertation ), Available from ProQuest Dissertations \& Theses database. (UMI No. 3409336 )

[13] Lustig, M. W., \& Koester, J. (2006). Intercultural competence: Interpersonal communication across cultures (5th. ed.). Boston: Allyn\& Bacon.

[14] Marr, J.D. (2009). Interpersonal communication and professional relationships between faculty and administrators in higher education (Doctoral dissertation).Available from ProQuest Dissertations \& Theses database. (UMI No. 3344666)

[15] Pascarella, E. T., \&Terenzini, P. T. (2005). How college affects students: A third decade of Research (2nd ed.) San Francisco, CA: Jossey-Bass.

[16] Wiersma, W. \&Jurs, S. G. (2005). Research methods in education (8th ed.). Boston, MA: Pearson Education. 